\title{
CASE OF CONGENITAL CYSTIC EYE AND ACCESSORY LIMB OF THE LOWER EYELID*
}

\author{
BY
}

\author{
N. S. C. RICE \\ Department of Pathology, Institute of Ophthalmology, London, \\ AND \\ S. P. MINWALLA AND J. H. WANIA \\ Masoomeen General Hospital, Karachi, Pakistan
}

\section{Case Report}

A female child first presented at the age of 8 months. Since birth the left eyelids had failed to open and were showing increasing distension. In addition, there was a protuberance from the left lower eyelid, also present since birth (Fig. 1). On examination, the left orbit was found to contain a cystic swelling which distended the upper lid, while projecting from the left lower lid was a rudimentary accessory limb. Examination of the right eye and orbit revealed no abnormality.
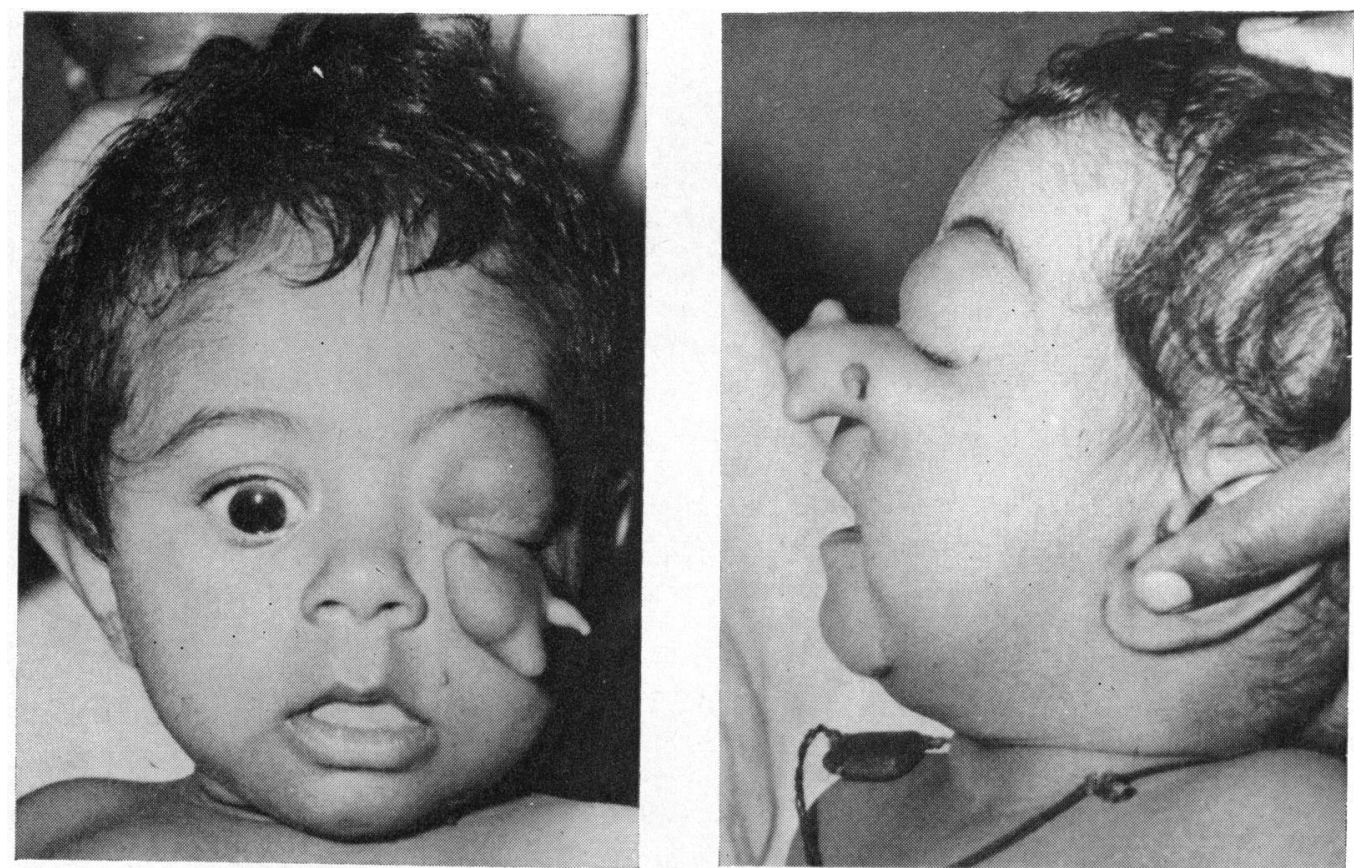

Fig. 1.-Congenital cystic eye and accessory limb of the lower eyelid. External appearance of the child.

The child, who is of Pakistani parents, is normally developed in other respects. When first seen she was suffering from a respiratory infection and anaemia which responded to treatment. The mother, who is approximately 22 years of age, experienced an uneventful pregnancy and delivery. There is no history of developmental deformities in the family.

The accessory limb was excised and was found to be joined to the maxilla by a well-formed joint with a capsule and articular cartilage. Exploration of the orbit revealed a large cyst which

* Received for publication February 9, 1965. 
was covered by conjunctiva anteriorly and was adherent to a mass of fibrous tissue posteriorly; some rudiments of the extra-ocular muscles were found. The cyst was excised.

Histopathological Report.-The orbital cyst was thick walled and unilocular and contained clear fluid. A mass of tissue projected into the cavity from the posterior aspect (Fig. 2). Microscopical examination revealed the wall to be composed of vascular connective tissue with fairly marked perivascular lymphocytic infiltration. The cavity was lined by cells with oval, palely staining nuclei sparsely scattered in an acellular matrix, but there was no clear evidence of attempted formation of retinal tissue; posteriorly the lining cells contained fine pigment granules. In some parts the lining was deficient, elsewhere it contained glial tissue which had proliferated posteriorly to form the mass projecting into the cavity (Fig. 3). No evidence of a lens was found. The posterior aspect of the cyst was associated with some sclera, striated muscle, nerves, and calcium deposits. The diagnosis was that of congenital cystic eye.

The accessory limb carried two nipple-like projections and one finger-like process; centrally there was a rudimentary limb bone together with some aberrant skin (Fig. 4, overleaf). It was covered by pigmented hairy skin with many sebaceous and sweat glands. The substance of the limb consisted of fat, striated muscle, nerve fibres, and bone.

\section{Discussion}

Congenital cystic eye results from failure of invagination of the optic vesicle; a cyst of neural ectoderm remains which becomes clothed with fibrous tissue. This case demonstrated many features of the condition (Mann, 1957). The lining of the cyst may remain as a single layer of neural epithelium but more commonly shows some differentiation into retinal tissue, with an ill-formed, inverted retina anteriorly, while posteriorly the cells contain pigment and represent the pigment epithelium. The retinal tissue may be replaced by proliferating glia.

The fibrous tissue wall is developed from mesoderm and represents sclera; the presence of perivasculitis has been reported previously (Calmettes, Bimes, and Déodati, 1948; Vancea, 1957), and perhaps this inflammation is responsible for the partial destruction of the lining seen in the case reported here. The extra-ocular muscles form and are inserted into the cyst wall but they are often fused.

If development is arrested at a somewhat later stage invagination occurs to a varying degree with corresponding differentiation of ocular structures. Congenital non-attachment of the retina represents considerable, though incomplete, invagination.

Clinically, the cyst is usually evident at birth, but it may be so small as to lead to the diagnosis of primary anophthalmos. The main differential diagnosis is from microphthalmos with cyst, which originates at a later stage of development and is due to defective closure of the embryonic cleft. In order to make the latter diagnosis it is necessary to demonstrate the microphthalmic eye which may only be apparent after tapping the cyst or on histopathological examination. A clinical sign which may be of value is that congenital cystic eye tends to distent the upper lid, but microphthalmos with cyst usually causes protrusion of the lower lid.

Although accessory limbs have been described in numerous bizarre sites they appear to be very rare in the region of the eye. Ahlfeld (1880) describes and illustrates in his Atlas a case with a limb and buttock protruding from the orbit associated with an encephalocele. The only comparable case to the one described here is that of Ladenheim and Metrick (1956); the child they described had bilateral microphthalmos with cyst, diagnosed clinically, with skin appendages on the left side of the face and commissure labialis. 
(a)

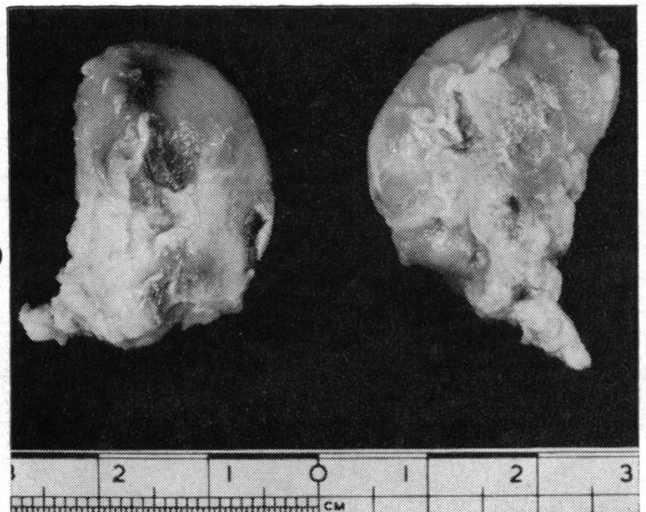

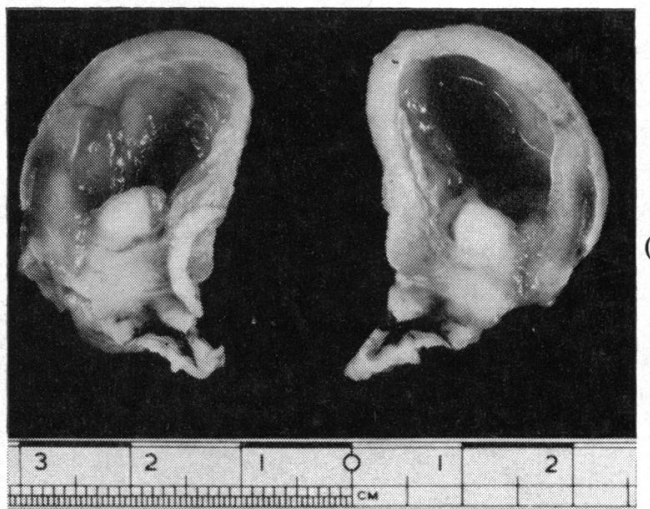

(a) External appearance. (b) Opened to

(b)

Fig. 2.-Mact
show cavity.

(a)

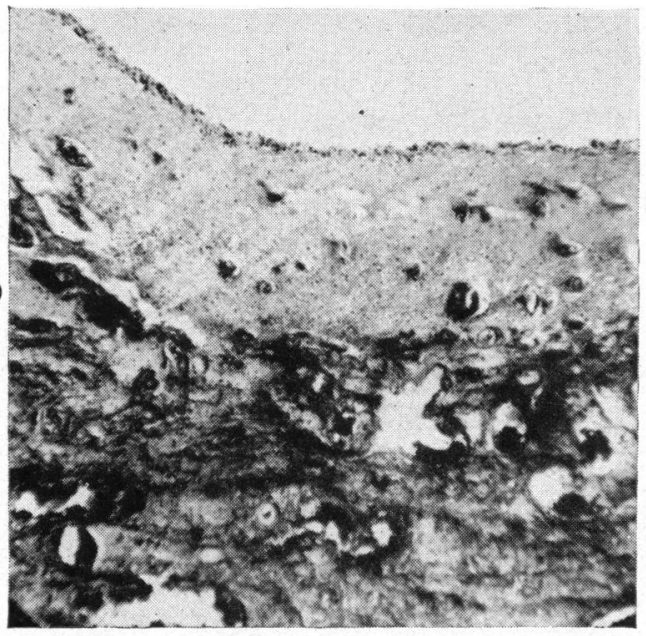

(c)

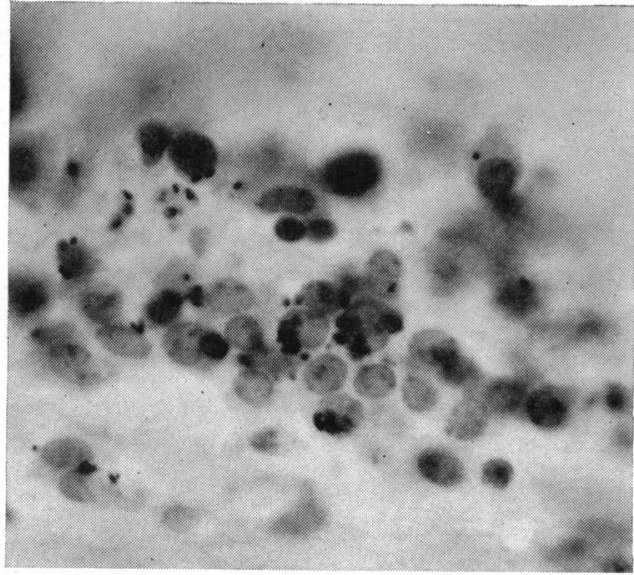

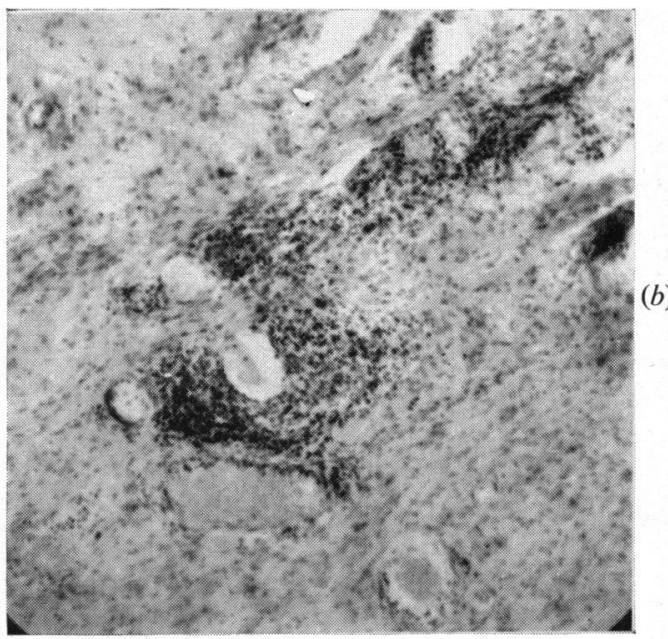

(b) 


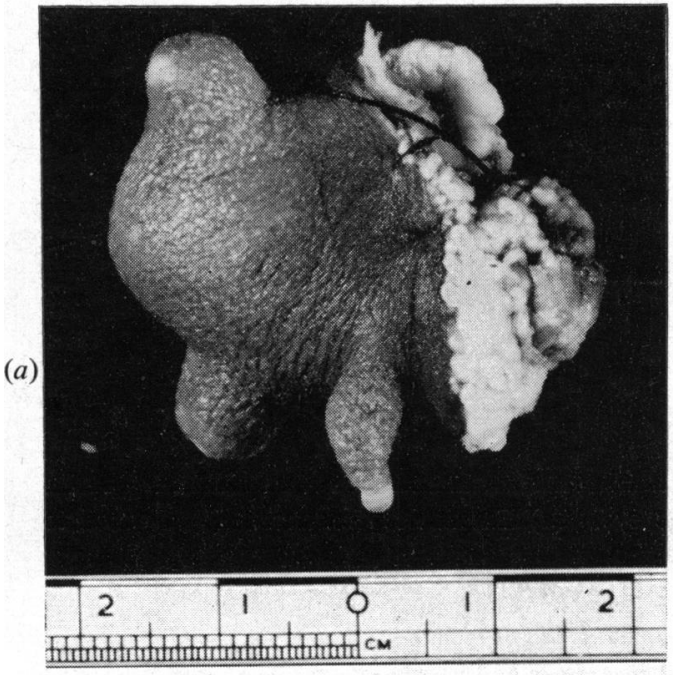

FIG. 4.-Macroscopic appearances of accessory limb. rudimentary limb bone.

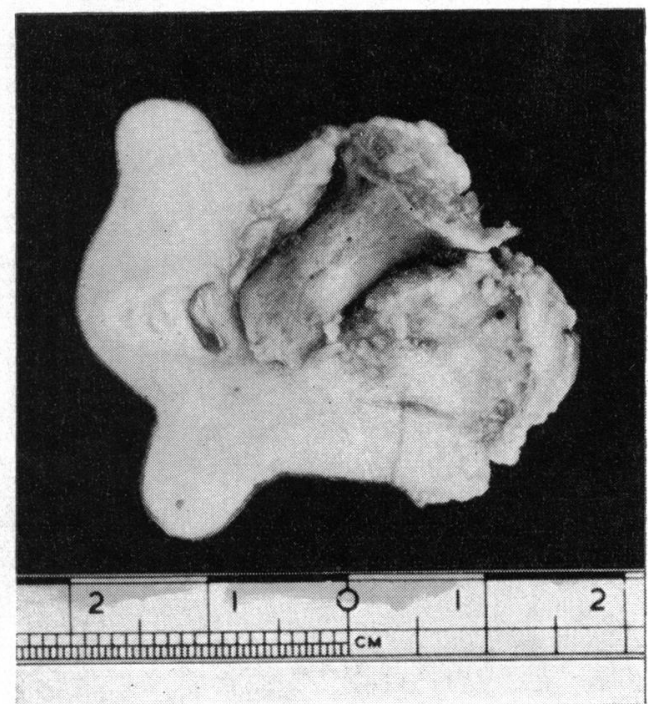

(a) External appearance. (b) Sectioned to show

Accessory limbs are a reflection of the pluripotency of the cells of the embryo during the early stages of development, a property which becomes progressively restricted as development proceeds. Abnormal differentiation of such cells may result from a disturbance of the relationship between organizers and tissues early in embryonic life; it is seen in its grossest form in homozygous twins while conjoined twins and accessory parts originate at later stages.

While many teratogenic agents have been recognized under both experimental and clinical conditions the cause in most instances cannot be determined; this is true of this case. However, the close association of the accessory limb and cystic eye in an otherwise normal child suggests that they are related. Certainly they both originated very early in embryonic life, the cystic eye between the 2 and $7 \mathrm{~mm}$. stages and the accessory limb probably earlier. It is possible that both abnormalities were the result of the action of a common agent; on the other hand, one may have followed as a consequence of the prior development of the other. It seems unlikely that failure of the optic vesicle to invaginate could have led to the development of the accessory limb. However, the converse might be true, the arrested development of the optic vesicle being secondary to the abnormal conditions affecting the surface ectoderm. This case showed no evidence of the formation of a lens and it may be that this was the significant factor in the origin of the cystic eye. The experimental work of Reyer (1954) may be cited in support of this hypothesis, for he found that removal of the lens could lead to failure of invagination of the optic vesicle; the implication was that the presence of a lens is necessary for the proper development of the neuro-ectoderm. It should be pointed out, however, that there is also evidence that the power of invagination of the optic vesicle is self-determined (Strangeways and Fell, 1926). 


\section{Summary}

A case is described of a female infant with a congenital cystic eye and an accessory limb of the lower eyelid. The errors of development responsible for each condition are discussed and a possible explanation for their association is proposed.

Our thanks are due to Prof. Norman Ashton for his help and guidance in the preparation of this paper.

\section{REFERENCES}

AhlfEld, F. (1880-82). " "Die Missbildungen des Menschen”. Grunow, Leipzig.

Calmettes, Bimes, and Déodati. (1948). Arch. Ophtal. (Paris), N.s. 8, 372.

Ladenheim, J., and Metrick, S. (1956). Amer. J. Ophthal., 41, 1059.

MANN, I. (1957). "Developmental Abnormalities of the Eye", 2nd ed. B.M.A., London.

REYer, R. W. (1954). J. exp. Zool., 125, 1.

Strangeways, T. S. P., and Fell, H. B. (1926). Proc. Roy. Soc. B., 99, 340.

VANCEA, P. (1957). Ophthalmologica (Basel), 134, 405. 